\title{
Casale Monferrato, Milán, Piacenza: tres catedrales revisitadas
}

\author{
Casale Monferrato, Milan, Piacenza: Three Revisited Cathedrals
}

Luigi Leoni · Fondazione Frate Sole, Pavia (Italia), arch.luigileoni@libero.it

Recibido: $22 / 07 / 2019$

Aceptado: 28/12/2019

(e) BY:NC https://doi.org/10.17979/aarc.2020.7.0.6291

\section{RESUMEN}

El Concilio Vaticano II expresó normas para la instalación litúrgica de presbiterios, una guía para el diseño de nuevas iglesias. Para la adaptación de los presbiterios de las iglesias anteriores al Concilio, las propuestas de intervención, diversificadas en tiempo y espacio, han encontrado cumplimiento donde no había necesidad de preservar elementos de alto valor patrimonial. En cambio, fue arduo trabajar en edificios históricos, con elementos de alto valor artístico. Es útil considerar ejemplos significativos para verificar las soluciones adoptadas y para favorecer un análisis de las intervenciones.

Las catedrales italianas de Casale Monferrato, Milán y Piacenza se toman en consideración para resaltar los criterios que llevaron a una comparación fructífera entre arquitectos, artistas y liturgistas a fin de adoptar soluciones adecuadas para las áreas presbiterales. La investigación destaca en algunos contextos propuestas para la mejora de obras de arte existentes, y en otras, nuevas esculturas en armonía con el complejo arquitectónico.

\section{PALABRAS CLAVE}

Arquitectura religiosa, Italia, catedrales, Concilio Vaticano II, areas presbiteriales.

\section{ABSTRACT}

Vatican II expressed norms for the liturgical installation of presbyters, a guide for the design of new churches. For the adaptation of the presbyters of churches before the Council, the proposals for intervention, diversified in time and space, have found fulfillment where there was no need to preserve elements of high patrimonial value. Instead, it was arduous to work in historic buildings, with elements of high artistic value. It is useful to consider significant examples to verify the solutions adopted and to favor an analysis of the interventions.

The Italian cathedrals of Casale Monferrato, Milan and Piacenza are taken into consideration to highlight the criteria that led to a fruitful comparison between architects, artists and liturgists in order to adopt adequate solutions for the presbyteral areas. The research highlights in some contexts proposals for the enhancement of existing works of art, in other new sculptures in harmony with the architectural building.

\section{KEYWORDS}

Religious Architecture, Italy, Cathedrals, Vatican II, Presbyteral Areas.

Cómo CITAR: Leoni, Luigi. 2020. «Casale Monferrato, Milán, Piacenza: tres catedrales revisitadas». Actas de Arquitectura Religiosa Contemporánea 7: 64-77. https://doi.org/10.17979/aarc.2020.7.0.6291. 


\section{CELEBRACIÓN DE LA BELLEZA}

Estudios e investigaciones llevados a cabo en los últimos años en numerosas regiones de Italia con la publicación de textos encomiables sobre la adecuación litúrgica de las catedrales, patrocinados por el Departamento del Patrimonio Cultural de la CEI, han puesto de manifiesto la precariedad de la situación actual, varias décadas después del Concilio Vaticano II (Della Longa et al. 2002 y 2007; Grisi y Lilli, 2011; Santi 2016).

En muchos casos nos encontramos en presencia de ejemplos provisionales. En las soluciones definitivas, a menudo nos topamos con un escaso valor artístico de las obras realizadas; lo que falló, sobre todo, fue el coraje, sin prejuicios, de aceptar el lenguaje contemporáneo del arte.

En la Iglesia siempre se celebró la belleza, entendida como una combinación armoniosa de arte y misticismo, destacando la calidad principal que alcanza la arquitectura de una iglesia - junto con cada una de las obras de arte conservadas en ella- al convertirse en un lugar de exaltación espiritual. Aquí es precisamente donde reside el secreto, que no se puede explicar fácilmente en términos sensibles. Cuando hablamos de lo espiritual entramos en un campo en el que aceptamos un misterio.

Si es una celebración de la belleza, no lo es en el sentido ambiguo de esteticismo vacío como un fin en sí mismo, sino en el sentido de una fuerte referencia a los valores auténticos y verdaderos del espíritu, que elevan el corazón y la mente hacia lo sublime. Juan Pablo II definió el arte como «una apertura a lo profundo, al otro, a lo inexpresable de la existencia, un camino que permite al hombre ser libre ante el misterio, traduciendo su ansiedad, loa cual no dispone de otras palabras para expresarse» (Juan Pablo II 1999).

Los obispos italianos, en el documento Spirito Creatore, que contiene propuestas y sugerencias para promover la pastoral de los artistas y del arte, publicado en el segundo año como preparación para el Jubileo 2000, dedicado al Espíritu Santo, afirman, en la introducción, que el arte es un don del Espíritu hecho a algunos para el bien de todos en la iglesia y que todo lo bello y positivo que ocurre en el mundo es obra del Espíritu Santo (CEI 1997).
Más allá de las declaraciones de principios, ampliamente compartidas, sigue existiendo la dificultad de aplicar los criterios de juicio a las distintas expresiones creativas en el mundo contemporáneo.

\section{REFLEXIONES GENERALES}

Es bien sabido que en el siglo pasado el esfuerzo de la Iglesia consistió en reanudar el diálogo con los artistas, que se vio interrumpido en las primeras décadas del siglo XX, para luego ser reanudado con dificultad en la segunda posguerra. Aún así, permanece la complejidad de los problemas relacionados con la necesidad de lograr una armonización de varios componentes, de expresar con una coordinación sabia una distribución de lugares y caminos anclada a la síntesis poética de la creación artística.

Luego, hay que registrar que en un mundo en rápido desarrollo, inclinado a celebrar superficialmente la imagen exterior de las cosas sensibles, más para ser disfrutada que para ser contemplada, es innegable la dificultad de identificar los valores más profundos que hablan al corazón más que a los ojos materiales. Pero a menudo es aún más difícil para los profesionales encontrar un consenso compartido sobre las prioridades a destacar.

El espacio arquitectónico y todo lo que a través de los elementos arquitectónicos y escultóricos, contribuye de manera significativa a hacer visible el misterio de la salvación, llevan a vivir profundamente lo que queremos anunciar, a través de la palabra, con la transmisión del mensaje del evangelio. Aún más importante, por lo tanto, será revestir esos espacios de sabiduría espiritual, y no sólo de observancia de indicaciones - loables e indispensables - dictadas por normativas que constituyen el fundamento en que se basa nuestro buen trabajo.

Para que se tenga una idea clara, si por un lado es indudablemente necesario comprometerse para que sean respetados y valorizados - tanto litúrgica como funcionalmente - todos los componentes adecuados para formalizar los espacios que se pretenden dedicar al culto, por otro lado es aún más esencial esforzarse por resaltar el misterio a través de creaciones de alto valor que hablen al corazón y que comuniquen entre sí, por lo que es inherente a ellas, la belleza del mis- 
terio que se ha de vivir plenamente. Se necesita ese fuego, que siempre ha tocado el corazón de los artistas, para que las obras sensibles no sean puramente estilísticas, sino que estén dictadas por un impulso original a traducir lo inefable, tal como lo definió san Pablo VI en sus escritos.

En el documento Spirito Creatore anteriormente mencionado, si por un lado los obispos afirman que la liturgia ha sido durante siglos y sigue siendo un terreno ideal de encuentro entre la Iglesia y el arte, por otro lado, también expresan la convicción de que la liturgia, para ser ella misma, merece lo mejor desde un punto de vista artístico. Los obispos esperan que los artistas ayuden a las iglesias a convertirse en lo que están llamadas a ser: «signos sensibles de las realidades celestiales» (CEI 1997). El arte no es un lujo ni una superestructura, ella coopera en «hacer que el mundo del Espíritu, de lo 'Inefable', sea accesible e incluso conmovedor» (Pablo VI 1964).

Asimismo, los obispos reiteran que «la liturgia requiere manifestaciones de formas de calidad elevada» (CEI 1997). La calidad arquitectónica y artística, si es verdadera, resume en sí todas las otras calidades funcionales.

Es siempre y solamente a través de la iluminación espiritual que se consigue producir una obra de arte, la cual, a pesar de ser una síntesis armoniosa de valores resultantes del conocimiento de cada disciplina, llamada a aportar su contribución para la realización de buenas obras, es, por otro lado, esencialmente un gesto procedente de un sabio abandono al Espíritu Santo, que guía la mano, la mente y el corazón del artista.

Todavía vivimos en un tiempo en el que la desconfianza hacia cualquier expresión surgida de la investigación artística contemporánea, se manifiesta con un repliegue en formas pertenecientes al pasado, lo que fue bien expresado por Antonio Marchesi y Giorgio Della Longa en sus ensayos sobre las catedrales de Emilia Romagna (Della Longa et al 2007).

El padre Costantino Ruggeri, a lo largo de su larga actividad artística, y nosotros, un equipo de arquitectos junto con él, hemos abordado el tema de la adaptación litúrgica de los presbiterios, enfrentándonos con las dificultades inherentes al problema, especialmente en

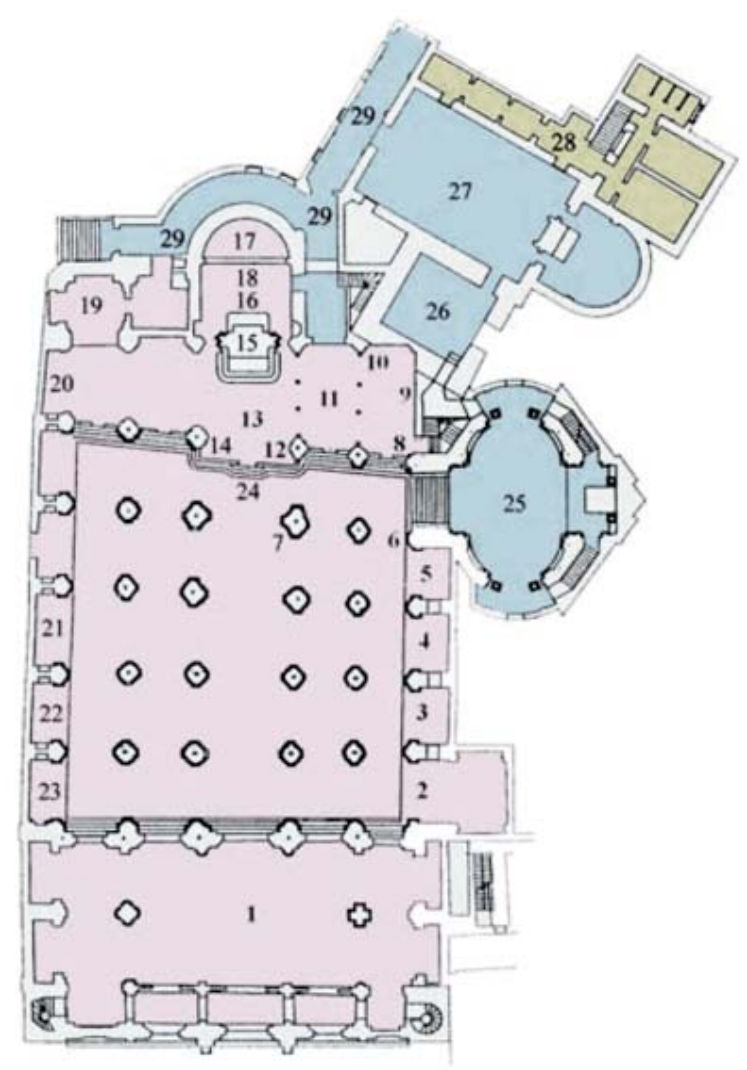

Fig. 01. Catedral de Sant'Evasio, Casale Monferrato (Italia); planta.

1. Atrio-nartex; 2. Capilla Magdalena; 3. Capilla de la Consolata; 4. Capilla de san José; 5 . Capilla de san Lorenzo; 6. Fragmento de columna; 7. Púpito, s. XIX; 8. Acceso a la cripta; 9. Monumento Gambera, s. XVI; 10. Capilla de la Madonna delle Grazie; 11. Tribuna del órgano, s. XII; 12. Ambon con Agnus Dei, s. XII; 13. Mensa, s. XII; 14. Cátedra episcopal, 1978; 15. Altar mayor, s. XVIII; 16. Coro, s. XVIII; 17. Vitral, s. XIX; 18. Pinturas murales, s. XIX; 19. Capilla del Santísimo Sacramento; 20. Monumento Tibaldeschi, s. XVI; 21. Capilla de santa Ágata y santa Apolonia; 22. Capilla de santa Lucía; 23. Capilla de la Virgen de Fátima; 24. Crucfijo románico, s. XII; 25. Capilla de san Evasio; 26. Torre campanario; 27. Sacristía; 28. Sala capitular; 29. Deambulatorio. 

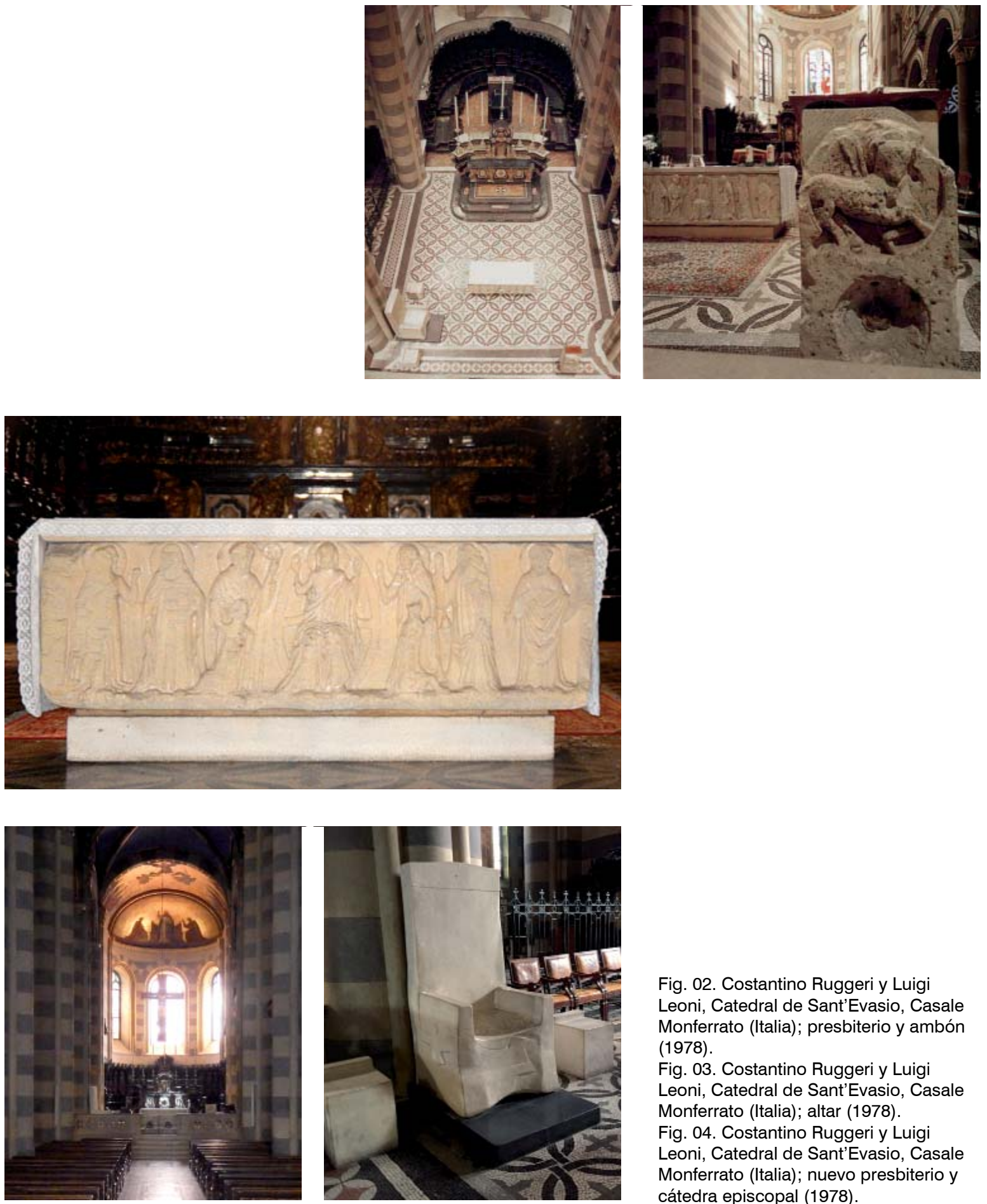

Fig. 02. Costantino Ruggeri y Luigi Leoni, Catedral de Sant'Evasio, Casale Monferrato (Italia); presbiterio y ambón (1978).

Fig. 03. Costantino Ruggeri y Luigi Leoni, Catedral de Sant'Evasio, Casale Monferrato (Italia); altar (1978).

Fig. 04. Costantino Ruggeri y Luigi Leoni, Catedral de Sant'Evasio, Casale Monferrato (Italia); nuevo presbiterio y cátedra episcopal (1978). 


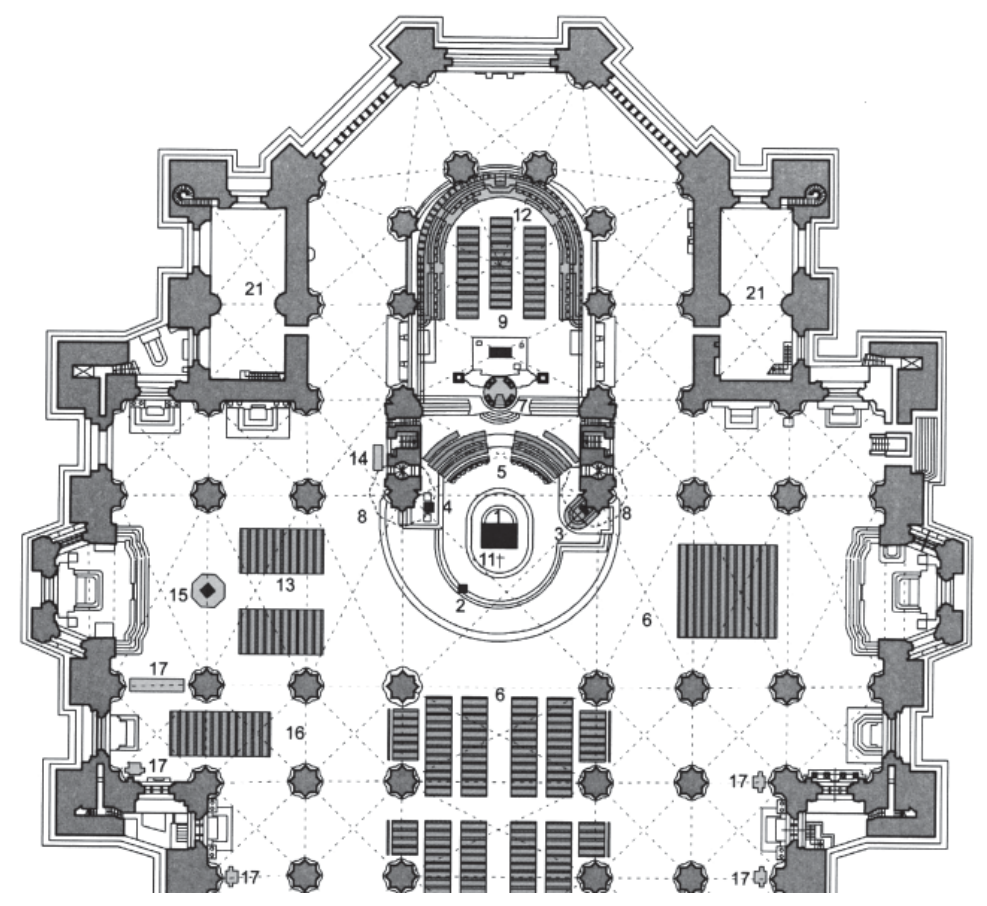

Fig. 05. Fabbriceria del Duomo, Catedral de la Natività della Beata Vergine María, Milán (Italia); planta adecuación litúrgica del presbiterio (1986).

1. Altar; 2. Ambón; 3. Cátedra; 4. Sede; 5. Canónigos; 6. Asamblea; 7. Sagrario; 8. Púlpitos; 9. Capilla ferial; 10. Fuente bautismal; 11. Cruz suspendida; 12. Coro lígneo; 13. Cantores; 14. Órgano; 15. Candelabro Trivulzio; 16. Capilla penitencial; 17. Confesionarios; 18 . Capilla del Crucifijo; 19. Capilla de la Madonna dell'Aiuto; 20. Pilas de agua bendita; 21. Sacristía.

En la página siguiente:

Fig. 06. Fabbriceria del Duomo, Catedral de la Natività della Beata Vergine María, Milán (Italia); nuevo presbiterio y detalles altar; cátedra episcopal y ambón (Mario Rudelli) (1986).

Fig. 07. Fabbriceria del Duomo, Catedral de la Natività della Beata Vergine María, Milán (Italia); adecuación litúrgica del presbiterio (1986). lo que respecta al debate con los comitentes y con las figuras encargadas de proteger el patrimonio cultural y artístico de las iglesias en Italia.

Al ser llamados a proponer soluciones para los presbiterios de las catedrales, hemos preparado diseños y modelos para la realización de nuevas esculturas de altares, ambones y cátedras episcopales. Mostramos algunos ejemplos de los mismos, que revelan los principios inspiradores de nuestra investigación en este campo específico.

\section{CASALE MONFERRATO}

La catedral, de origen muy antiguo -y que es, de hecho, una de las catedrales más importantes del estilo románico de Piamonte-, sufrió varias modificaciones y renovaciones a lo largo de los siglos, la más importante de las cuales se remonta al siglo XIX, cuando el edificio fue renovado en estilo neorrománico según el criterio del tiempo; pero más recientemente fue objeto de restauraciones a finales del siglo pasado y principios del nuevo milenio (Fig. 01).
La adecuación litúrgica del presbiterio fue llevada a cabo en los años setenta del siglo pasado. El altar mayor en mármoles policromados, que se remonta, al igual que los estalos de madera de la sillería del coro, a la primera mitad del siglo XVIII, se ha conservado como lugar de la Custodia Eucarística. Aparece en el ábside, colocado por detrás, lo que favorece la articulación y el desarrollo de los polos litúrgicos de acuerdo con las normas conciliares en el espacio anterior, donde se colocaron el altar, dirigido hacia los fieles, el ambón y la cátedra episcopal (Fig. 02). También se conservaron las balaustradas que rodeaban el espacio del presbiterio, que se eleva de cinco escalones del plano de las naves.

En el ámbito del debate que se inició sobre el rumbo a seguir para proponer los nuevos elementos para las acciones litúrgicas, la introducción de esculturas contemporáneas no fue aceptada, hecha excepción de la cátedra episcopal, obra realizada por el padre Costantino Ruggeri y por el autor en piedra de Vicenza en 1978. La composición del nuevo altar 

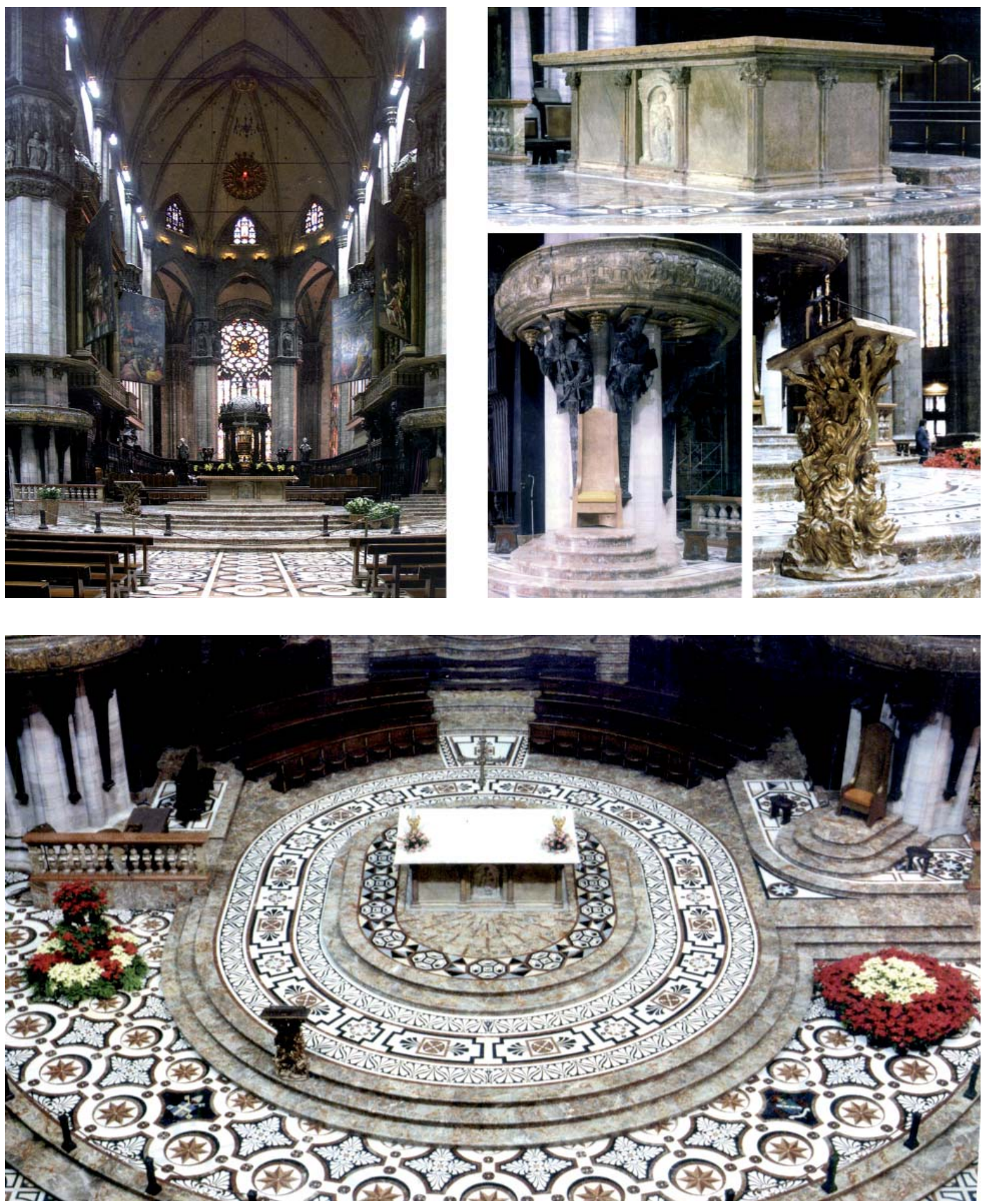

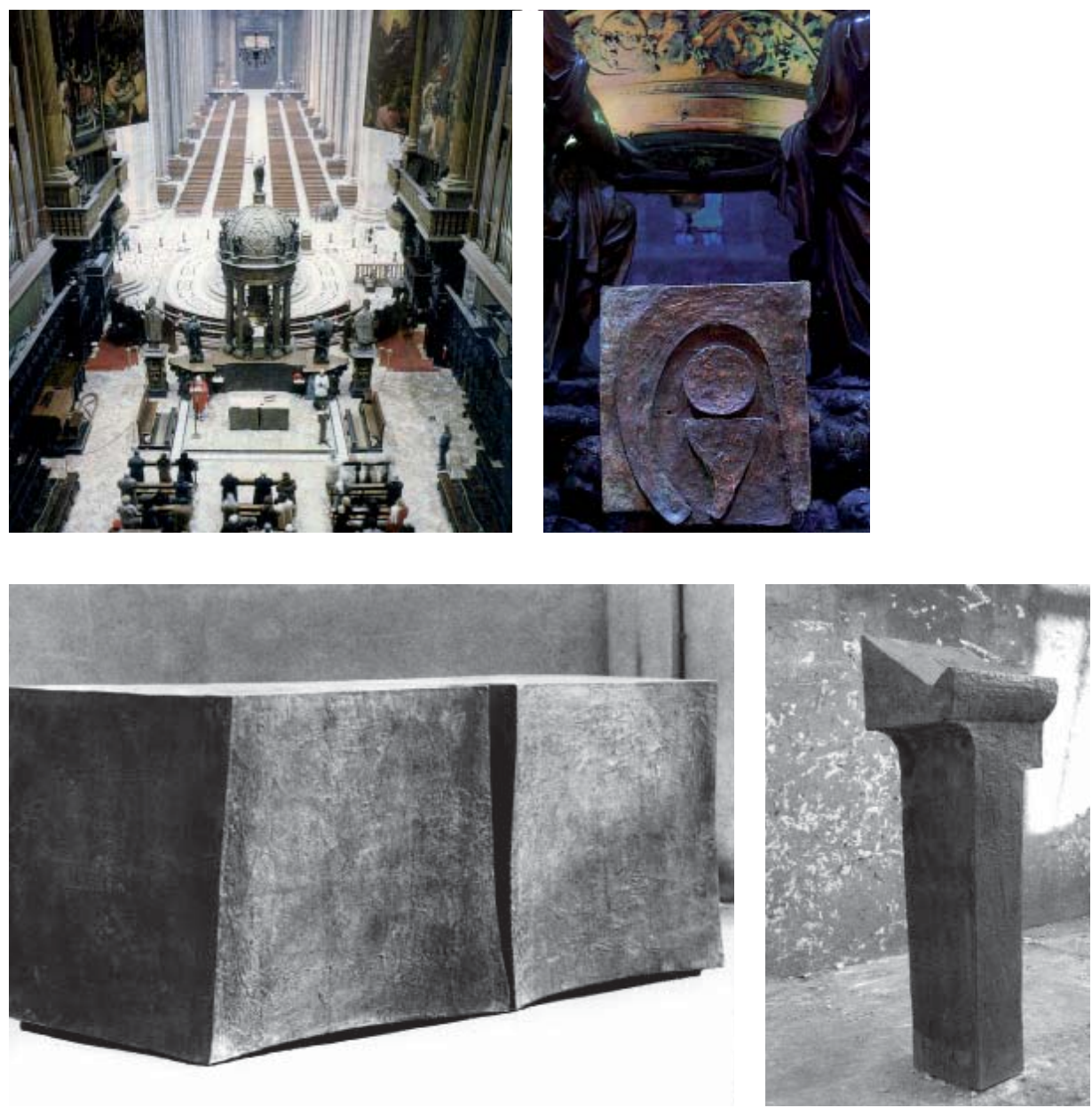

Fig. 08. Costantino Ruggeri y Luigi Leoni, Catedral de la Natività della Beata Vergine María, Milán (Italia); detalles del tabernáculo de la capilla invernal.

Fig. 09. Costantino Ruggeri y Luigi Leoni, Catedral de la Natività della Beata Vergine María, Milán (Italia); altar, escaño del celebrante y ambón de la capilla invernal.

Fig. 10. Costantino Ruggeri y Luigi Leoni, Catedral de la Natività della Beata Vergine María, Milán (Italia); detalles del altar y el ambón de la capilla invernal.

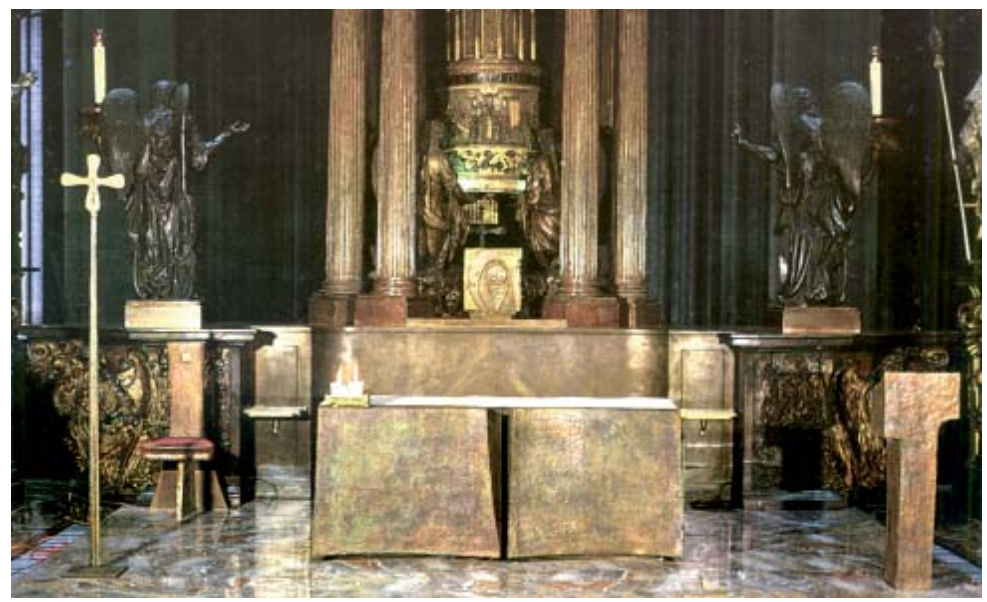


se realizó reutilizando un sarcófago de arenisca que data del siglo XII, presente en el atrio de la catedral. En él está representada la figura de Cristo enmarcada en una almendra central junto con seis santos y dos devotos arrodillados. Sobre ella se colocó una mesa hecha con un bloque macizo de arenisca. Incluso el ambón es un vestigio muy noble en términos de factura y antigüedad, pudiéndose asimismo fechar en la época del sarcófago utilizado para el altar. Se trata de un fragmento de un monolito procedente de la fachada del Duomo (catedral) y muestra una representación del Agnus Dei. Apenas emerge de la balaustrada, hallándose colocado más allá de ésta (Fig. 03).

La cátedra episcopal se encuentra ubicada lateralmente, apoyada contra el pilar izquierdo del presbiterio, en armonía - en cuanto a forma y material utilizado - con las demás obras presentes (Fig. 04).

Colgado del arco triunfal, el gran crucifijo centra - con su marcada linealidad geométrica - el espacio curvo del cascarón del ábside. Fruto de la obra de uno o más artistas, de cuya historia no se ha transmitido ningún rastro, el hermosísimo Cristo está formado por un soporte de madera cubierto con placas de plata y cobre, colocado encima de la cruz de madera decorada, como la corona real en la cabeza de Jesús, con piedras duras y cristales de diferentes colores. Es una obra que data de la segunda mitad del siglo XII, la cual, colocada originalmente en la catedral de Alessandria, fue transportada a Casale Monferrato en 1403. La iconografía nos muestra a Cristo en la cruz aún vivo, erguido, sin signos de sufrimiento, según la tipología del Christus Triumphans del siglo XII. Esta preciosa obra - que presenta una analogía con crucifijos similares conservados en el Duomo de Vercelli, en el museo del Duomo de Milán y en la basílica de San Miguel el Mayor en Pavía - fue restaurada justo durante las obras de adecuación realizadas en 1978.

\section{MILÁN}

El Duomo de Milán —una catedral gótica dedicada a la Natividad de la Bienaventurada Virgen María-, se inició en 1386 y fue objeto de intervenciones y enriquecida con obras significativas a lo largo de todos los siglos hasta nuestros días.
Después del Concilio Vaticano II se sucedieron varias intervenciones encaminadas a la restauración provisional del presbiterio, de las cuales las dos primeras fueron realizadas en los años sesenta por parte del arquitecto mons. Enrico Villa, que preveían la preservación integral del antiguo presbiterio, la creación de un nuevo altar colocado en el centro del cimborrio, y la cátedra episcopal en el centro del nuevo coro de los canónigos sobre eje del altar y el tabernáculo.

Un tercer arreglo temporal se debe al arquitecto Ernesto Brivio, quien sentó las bases de la que sería la solución definitiva. La cátedra se colocó lateralmente, adosada al pilón, mientras que el ambón migra hacia el lado izquierdo, en una posición avanzada hacia los fieles.

La disposición actual del presbiterio se remonta a 1986 (Fig. 05). La Fabbriceria del Duomo se encargó personalmente del diseño de la nueva área presbiterial en una posición avanzada, incluyendo el estudio de las incrustaciones de mármol del pavimento con patrones florales que recuerdan motivos del pasado, presentes en la pavimentación de la sala eclesial.

El altar, que data del siglo VIII, está ubicado en el centro de la nueva amplia área presbiterial, en el punto de intersección entre los ejes de la nave central y del transepto (Fig. 06). La cátedra episcopal de bronce dorado, moldeada por el escultor Mario Rudelli, a la derecha del altar, se encuentra al pie del púlpito que la enmarca. El lugar de la Palabra se identificó en una posición avanzada con un nuevo ambón, también realizado por Mario Rudelli (Fig. 07).

El nuevo complejo se encuentra adelantado con respecto a los límites tradicionales constituidos por los pilones que sostienen los púlpitos, y está delimitado en la parte posterior por los estalos de los canónigos y por el ciborio con el tabernáculo y las esculturas de los santos Carlos y Ambrosio. Anteriormente, reproduce en planta una estructura semicircular. El área del presbiterio de Pellegrini fue recuperada, transformándola en una capilla para las celebraciones en los días laborables (Fig. 08).

En el espacio trasero del coro, el cardenal Carlo Maria Martini encargó al padre Costantino Ruggeri que realizara la capilla invernal (hiemal) en su totalidad. 

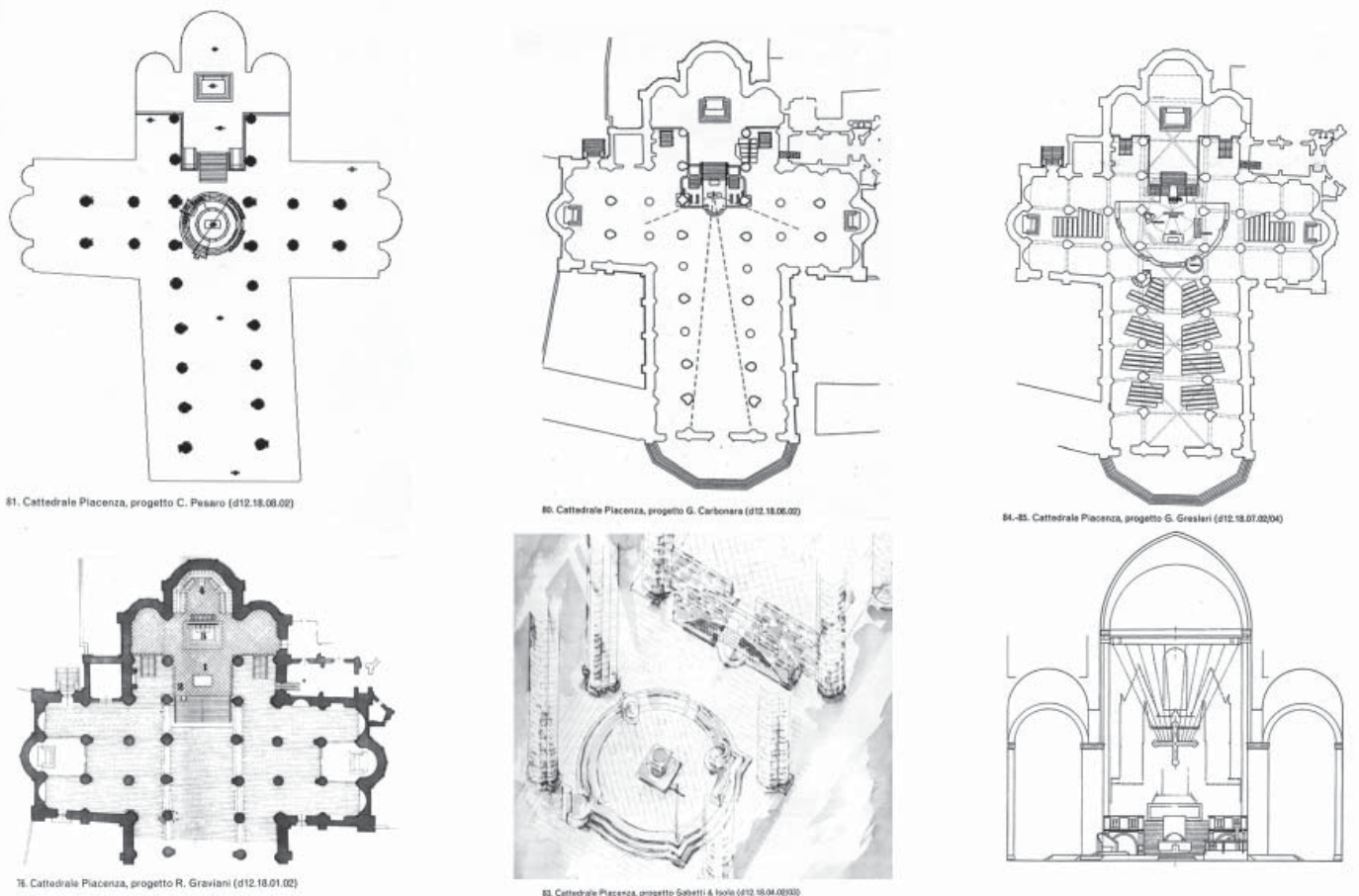

Fig. 11. Catedral de Santa María Assunta, Piacenza (Italia); propuestas de adecuación litúrgica del presbiterio de Pesaro, Carbonara, Gresleri, Graviani y Gabetti \& Isola (1999).

Fig. 12. Propuestas de Benedetti, Benzi y Barbieri (1999).

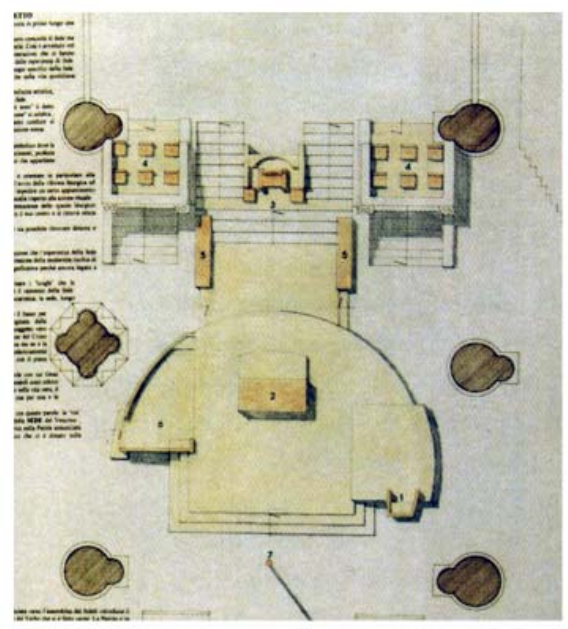

77. Cattedrale Piacenza, progetto E. De Benedetti (d12.18.02.02)

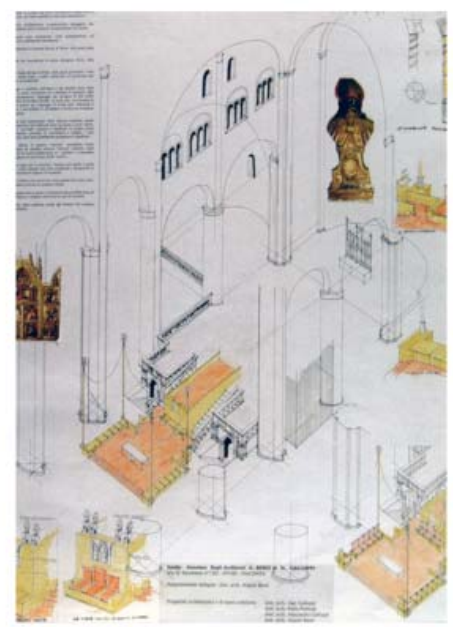

79. Cattedrale Piacenza, progetto A. Benzi (d12.18.05.02)

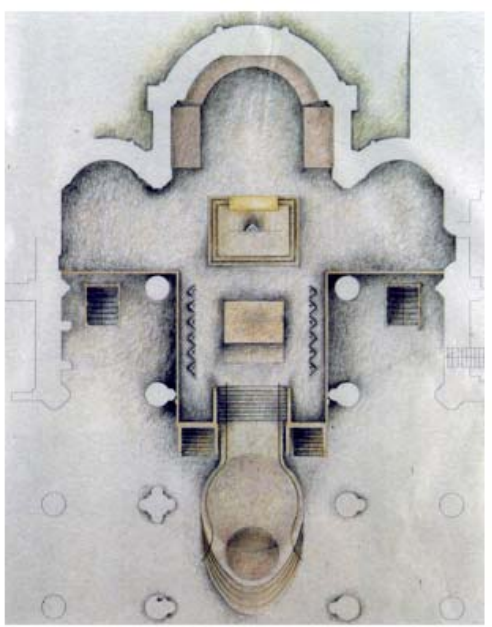

78. Cattedrale Piacenza, progetto F. Barbieri (d12.18.03.02) 
El padre Costantino - que había recibido la ordenación sacerdotal en 1951 en la catedral de Milán-, se dedicó fervientemente al estudio y a la realización de las esculturas, que concibió en bronce, con diseños y formas decididamente contemporáneos (Fig. 09). Su intervención afirmó que con el coraje de la creatividad es posible dialogar con el hombre de hoy, para que la Iglesia siga viva y demuestre su capacidad de hablar con el lenguaje de las expresiones artísticas contemporáneas.

En el volumen dedicado a esta obra, publicado en 1986, el propio padre Costantino habla de la emoción que el invadió al ser llamado a realizar el trabajo:

Nunca hubiera pensado... realmente nunca me atreví a pensar en entrar yo también en la catedral de Milán como un trabajador de sueños. De repente, en un momento en que estaba pensando más en refinar y reconsiderar todo mi trabajo en el campo de la pintura, de la escultura, de los vitrales $\mathrm{y}$ de arquitecturas de nuevas iglesias esparcidas en un mapa de amistades y experiencias que siempre me ha apasionado, hete aquí que recibí una invitación que me hizo 'temblar las venas y las muñecas' (...) Hete aquí que explotó la trépida y total felicidad que te crea en la mente, como si ya los hubieras dibujado en la hoja, la idea, el boceto, la imagen y el espíritu de lo que quieres crear. Un altar 'de diario' en el coro, en el ábside, dirigido al espacio tradicional de los canónigos. Casi un 'doble' del gran altar de Ambrosio y Borromeo, bajo el mismo ciborio triunfal, al lado del mismo tabernáculo erigido por voluntad de S. Carlos Borromeo... Traté de hacerlo todo con humildad y amor, limitándome a lo esencial, es decir, respetando la coherencia con mi trabajo. Una mesa desnuda, ya 'partida' al igual que un pan, el pan de todos los hombres, 'el pan de la vida eterna'. Y el tabernáculo, el ambón, la cruz, el escaño, el porta cirio y el jarrón de flores: todo ello con el menor número posible de signos y volúmenes... Las grandes vidrieras que coronan el ábside iluminan y pintan incesantemente el altar con una paleta natural inagotable, a cada hora del día, de esa luz con la que el Espíritu 'hizo que toda cosa estuviera bien hecha y fuera hermosa' (Ruggeri 1986, 1) (Fig. 10).

\section{PIACENZA}

La catedral de Piacenza, Santa Maria Assunta, dedicada a la Asunción de María - importante ejemplo de la arquitectura románica en Italia-, fue construida entre 1122 y 1233 sobre las ruinas del lugar de culto preexistente que se derrumbó tras el terremoto ocurrido en 1117 . Entre 1122 y 1160 se construyeron el área absidal, con la cripta, el transepto y los pasillos laterales. La fachada y la cúpula, en cambio, se terminaron más tarde. La construcción del campanario continuó hasta 1333.

En los siglos siguientes, la iglesia se enriqueció con decoraciones, capillas y altares, eliminados por la restauración realizada entre 1897 y 1902.

El interior se caracteriza por una planta en cruz latina y se compone de tres naves, divididas entre sí por veinticinco sólidos pilares cilíndricos. El transepto está también dividido en tres naves. En el punto de intersección se encuentra el cimborrio octogonal, decorado con frescos del siglo XVII. El presbiterio está colocado en posición elevada encima de una cripta en forma de cruz griega con 108 columnitas románicas, y acoge las reliquias de santa Justina, a la que se dedicó la primera catedral de la ciudad.

En 1998 se publicó la convocatoria de un concurso de ideas para la nueva disposición del área presbiterial de la catedral. Ocho grupos de profesionales fueron invitados a participar en el concurso, de los cuales algunos eran arquitectos locales y otros arquitectos conocidos a nivel nacional: todos tenían que recurrir a la ayuda de un experto en liturgia y de un artista. La operación fue muy difícil, teniendo en cuenta la considerable diferencia de altura entre el plano de la nave y el del presbiterio histórico situado encima de la cripta. Algunas propuestas se refieren al espacio del presbiterio histórico, interviniendo en su mayoría con soluciones de nueva realización en la base de la escalera que sube al presbiterio, pensando que esta era la manera correcta de experimentar las indicaciones proporcionadas por las notas pastorales publicadas sobre la adaptación de las iglesias a la Reforma litúrgica (CEI 1996) (Fig. 11).

En junio de 1999, el jurado proclamó ganador el proyecto del grupo formado por Pietro Gazzola y Carlo Pesaro, por su reversibilidad y pleno res- 


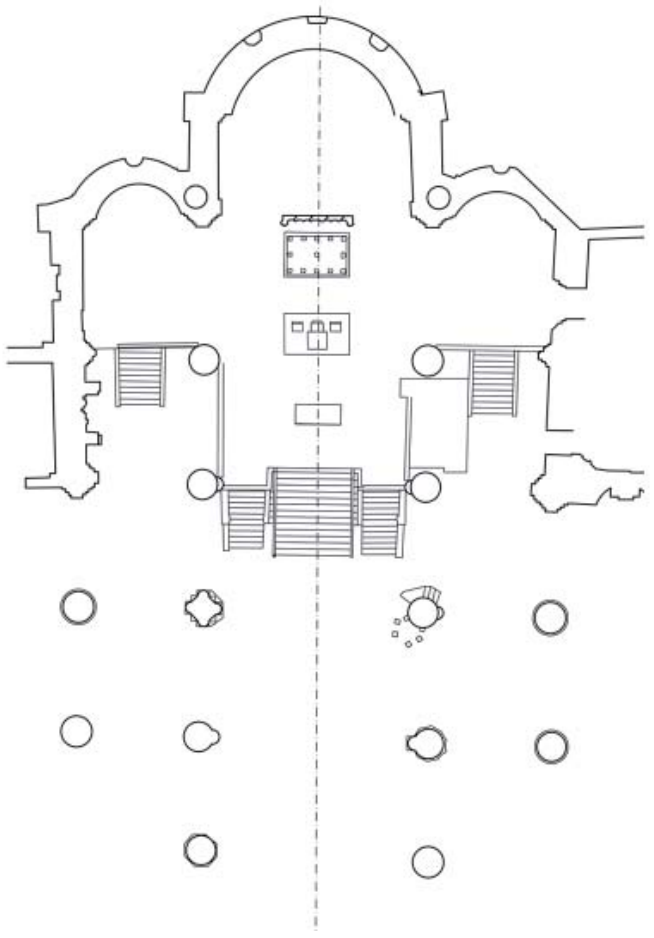

Fig. 13. Luigi Leoni y Chiara Rovati, Catedral de Santa María Assunta, Piacenza (Italia); adecuación litúrgica del presbiterio (2016-18).

Fig. 14. Luigi Leoni y Chiara Rovati, Catedral de Santa María Assunta, Piacenza (Italia); nuevo altar (2018). Fig. 15. Luigi Leoni y Chiara Rovati, Catedral de Santa María Assunta, Piacenza (Italia); nueva cátedra episcopal (2018).
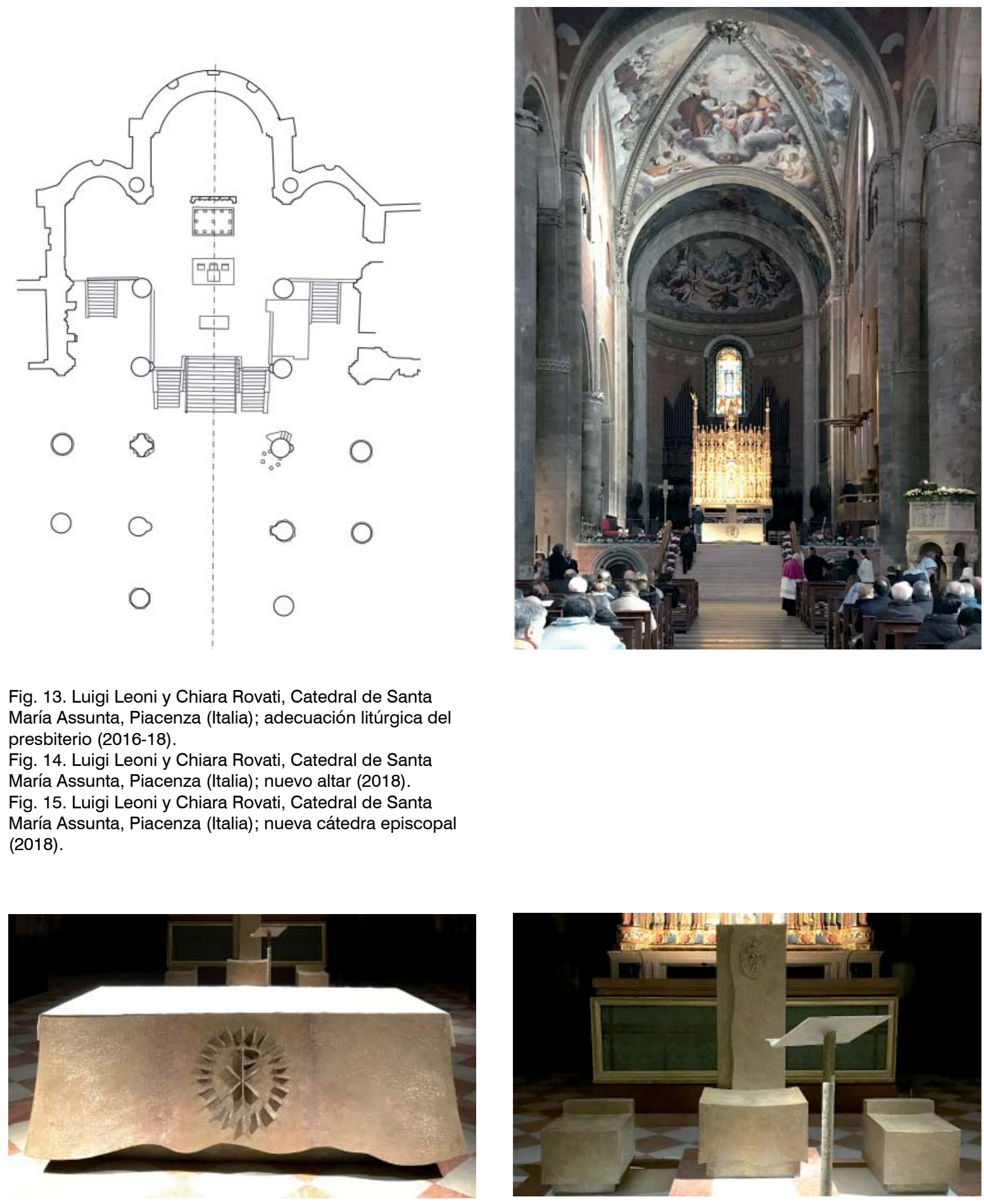
peto por lo existente: una plataforma circular en el punto de intersección entre la nave y el transepto independiente del antiguo presbiterio y de la escalera de acceso correspondiente. Al no haber obtenido la autorización de la Soprintendenza, la propuesta no se llevó a cabo. También en el crucero de la nave principal con el transepto se centraron las propuestas de Giovanni Carbonara, Gabetti \& Isola y Glauco Gresleri. La de Gabetti \& Isola preveía intervenciones sobre la estructura existente, mientras que la de Gresleri conllevaba la introducción de una gran cruz suspendida aprovechando el espacio vacío encima del nuevo altar, reproduciendo el intento creado por Gaudí en la catedral de Mallorca con la construcción del baldaquino (Fig. 12).

Las propuestas concernientes al espacio frente a los peldaños de ascenso a la altura del presbiterio histórico - tratando de involucrar los espacios del transepto para favorecer la participación activa de los fieles en las celebraciones eucarísticas según el Concilio Vaticano II- privilegiaban aspectos meramente funcionales y litúrgicos, pero dejaban sin resolver la armonización con la concepción arquitectónica original.

Cabe admitir que las catedrales - especialmente en presencia de criptas subyacentes al presbiterio, tal como ocurre en numerosos ejemplos históricos que se remontan a la época medieval- muestran cuán complejo es desarrollar soluciones capaces de satisfacer los múltiples componentes que hay que cumplir en la revisión de un espacio rico en intervenciones que se han ido sucediendo a lo largo de los siglos. Al querer examinar en detalle las propuestas de proyectos de los participantes al concurso convocados para su realización, lo que se pone de manifiesto es, sin duda, el compromiso profesional asumido por los arquitectos en proponer nuevas soluciones de acuerdo con las pautas sugeridas por las normas surgidas del Concilio Vaticano II. Las instancias planteadas por la visión de una participación activa de los fieles en las celebraciones eucarísticas y en los ritos sagrados sugirieron a la mayoría plantear un nuevo espacio presbiterial al pie de la escalera de ascenso al espacio histórico del presbiterio. En algunas propuestas, esta área está separada de los peldaños, en una configuración completamente autónoma del espacio elevado previamente diseñado para el altar, la cátedra episcopal y los asientos de los canónigos. Este espacio parece lejano, fuera de un contexto que permita dialogar con fuerza con las nuevas presencias. En otras propuestas, la nueva área parece estar unida a la escalera histórica, en un intento de producir una extensión del presbiterio original, casi una extensión que - sin embargo - desciende de nuevo hacia el nivel inferior, dialogando más con la nave que con el espacio posterior.

Ulteriormente a los años en que tuvo lugar el concurso, se crearon soluciones provisionales en un intento de verificar la validez de las propuestas a lo largo del tiempo. En 2016, cincuenta años después del Concilio Vaticano II, el obispo Gianni Ambrosio, queriendo proporcionar una solución definitiva para la disposición presbiteral, nos confió la tarea a los arquitectos Luigi Leoni y Chiara Rovati, del Studio Ricerca Arte Sacra de Pavía, que continuamos la actividad iniciada junto con el padre Costantino Ruggeri (Fig. 13).

En las numerosas inspecciones realizadas se verificó que, tras pasar el umbral de la catedral, la gran espacialidad de la nave central, con su impulso ascensional, lleva a elevar la mirada hacia el área que se encuentra encima de la escalera. El ojo, guiado por la secuencia de los peldaños, posa naturalmente la mirada en el nivel donde estuvo colocado el altar provisional, sobre el cual se alza la valiosa obra de arte constituida por el retablo de madera dorada del siglo $\mathrm{XV}$.

En este plano se propuso la colocación del nuevo altar, colocado sencillamente en el pavimento actual, sin otras mediaciones: una solución a privilegiar, considerando que el diafragma de la balaustrada, antaño existente, se acabó eliminando en intervenciones anteriores. El posicionamiento eminente asegura una visibilidad digna, incluso desde los puntos más distantes de la nave principal, y con el avance producido a dos metros de la escalera, muestra una centralidad para todo el espacio eclesial, lo cual hubiera sido difícil de alcanzar con otras soluciones (Fig. 14).

El altar es el símbolo de Cristo. Todo en la iglesia debe estar en función de este elemento fundamental 
para cada acción litúrgica; pero, por supuesto, incluso en ausencia de momentos litúrgicos, el altar debe aparecer como el corazón mismo del templo, irradiando fulgor. Así es como nació una escultura de bronce que expresa el poder con que obra el Espíritu Santo en el gran misterio eucarístico. La escultura, obtenida por fundición a la cera perdida, aparece brillante, con una aleación adecuada y pátinas protectoras que conservan el brillo a lo largo del tiempo. Su forma, pura y simple, tiene movimientos suaves diseñados para dar luminosidad y dulzura. Anteriormente, al igual que una gema preciosa, al sobresalir, se ha puesto de relieve el símbolo epigráfico del nombre de Cristo, rodeado por un rayo de luz. El esplendor y el brillo del color manifiestan la gloria del Hijo Unigénito que se ofreció por amor al Padre para darnos vida, tales rayos de luz para nuestra existencia.

La cátedra del Obispo, en consonancia con el altar, se resuelve en bronce, así como los dos asientos colocados a ambos lado de la misma, a la derecha y a la izquierda respectivamente (Fig. 15). En línea con la mesa, la cátedra se coloca en una posición central, elevada mediante dos peldaños para permitir una buena visibilidad. No está configurada como un trono, sino que quiere expresar fuerza y elegancia en la composición de elementos estrictamente esenciales y, al mismo tiempo, suaves. En el respaldo está representado, en bajorrelieve, el Buen Pastor llevando sobre sus hombros la oveja perdida, símbolo del ministerio pastoral del obispo.

Al lado del altar se levanta la cruz procesional diseñada para contemplar la gloria de Cristo.

Jesús en la cruz lleva los signos de la pasión con los agujeros en sus manos y pies y la herida en su costado, pero aparece separado de la cruz, rodeado por el abrazo del Espíritu. En su rostro sereno y en las actitudes tranquilas de su cuerpo ya se anuncia la resurrección. Jesús vive, en la obediencia al Padre, la paz y el gozo profundo del cumplimiento de la salvación para el hombre. Estamos lejos del suplicio del sufrimiento y del dolor humano experimentado en la cruz, lejos de complacernos en los signos que indican la pasión aceptada y vivida: las espinas clavadas en la cabeza y la sangre derramada que fluye sobre el cuerpo para empapar la tierra quemada del género humano. Es la glorificación del hijo amado por parte del Padre, una glorificación que va más allá de la agonía del condenado, para mostrar la serenidad y el amor imperturbable que rodea los sentimientos, la mente y el corazón de Jesús. En una mirada inalcanzable de amor, los ojos están abiertos a la luz, la posición es compuesta y suave, los brazos y las manos están abiertos para poder abrazar a toda la humanidad. Su rostro radiante, al mirarte, te acoge y te atrae hacia sí: él es quien nos da la vida, que nos abre a la esperanza segura de un mundo nuevo en el que la muerte es vencida y en donde se canta el aleluya de la resurrección.

El lenguaje se vuelve claro y descarnado, inmediato y libre de investigaciones altisonantes. La belleza cantada no es para la perfección estética de formas externas, sino dictada por el misterio vivido interiormente que habla en el secreto del alma.

Es significativa la presencia del púlpito histórico de piedra erigido de manera unitaria con el pilar en la intersección de la nave con el transepto que, desde siempre, ha sido reconocido como el lugar más adecuado para la proclamación de la Palabra de Dios. Por lo tanto, fue natural no diseñar un púlpito en lo alto del presbiterio, que habría disminuido la importancia del antiguo púlpito — privándolo de su funcionalidad litúrgica - para reducirlo a un simple elemento de interés histórico-artístico.

\section{CONSIDERACIONES FINALES}

Los estudios realizados en las décadas posteriores a la promulgación de las normas por parte de la Conferencia Episcopal Italiana para la adecuación litúrgica de los presbiterios - las propuestas presentadas son un ejemplo de ello- ponen de manifiesto cuán problemático y complejo es proponer soluciones definitivas. Cabe reconocer, por experiencia, que el trabajo de los equipos de los diversos operadores llamados a realizar la delicada tarea es particularmente difícil, especialmente, entre arquitectos, artistas y liturgistas, debido a las diferentes habilidades y a la diferente formación cultural que lleva a abordar el problema de maneras a menudo discordantes, favoreciendo ciertos aspectos en detrimento de los demás. 
Debemos decir que, sin duda, no se trata sencillamente de componer mobiliario litúrgico; ni siquiera es suficiente satisfacer sólo una nueva estructura litúrgica funcional. Se trata de diseñar una nueva armonía en espacios ricos en espiritualidad. Es preciso ser investidos del fuego creativo por el Espíritu Santo, tal como lo deseó san Pablo VI dirigiéndose a los artistas (Pablo VI 1964).

La catedral como iglesia-madre, iglesia-símbolo, lugar de identidad para los fieles, requiere una atención escrupulosa y una evaluación constante de las intervenciones que en ella resultan necesarias en cuanto al plan de la disposición celebrativa. De ahí la capacidad de trabajar con agudeza y competencia refinada para mostrar cómo es posible interpretar, con el lenguaje artístico contemporáneo, las nuevas visiones transmitidas mediante la Reforma litúrgica.

También cabe enfatizar que es preciso reiterar que la catedral es un monumento viviente, perteneciente a la comunidad, no pudiéndose por lo tanto considerar un museo para turistas que, cada vez más, atestan nuestras ciudades.

\section{BIBLIOGRAFÍA}

CEI. Commissione Episcopale per la Liturgia. 1996. L'adeguamento delle chiese secondo la riforma liturgica. Nota pastorale. Consultado el 27/09/2019. https://bit.ly/2zm2YXd.

CEI. Ufficio Nazionale per i Beni Culturali Ecclesiastici. 1997. Spirito Creatore. Proposte e suggerimenti per promuovere la pastorale degli artisti e dell'arte. Consultado el 27/09/2019. http://bit.ly/2D5YoyD.
Della Longa, Giorgio, Antonio Marchesi y Massimiliano Valdinoci, coord. 2007. Le cattedrali dell'Emilia-Romagna Storia, Arte, Liturgia. Lo stato di adeguamento delle chiese cattedrali della Regione Ecclesiastica Emilia-Romagna alla riforma liturgica del Concilio Vaticano II. Rovereto: Nicolodi.

Della Longa, Giorgio, Antonio Marchesi y Massimiliano Valdinoci, coord. 2002. Antichi spazi per la nuova liturgia. Le cattedrali del Triveneto. Rovereto: Nicolodi.

Grisi, Tino y Giampiero Lilli, coord. 2011. Le cattedrali della Lombardia, l'adeguamento liturgico delle chiese madri nella regione ecclesiastica lombarda. Cinisello Balsamo: Silvana.

Juan Pablo II. 1999. Carta a los artistas (4 de abril). Consultado el 07/06/2019, http://bit.ly/2riJS3S.

Pablo VI. 1964. 'Misa de los artistas' en la Capilla Sixtina (7 de mayo). Consultado el 22/09/2019, http://bit.ly/35oiYGB.

Ruggeri, Costantino. 1986. Duomo di Milano. Cappella feriale. Settimo Milanese: Barlocchi.

Santi, Giancarlo. 2016. Il Rinnovamento liturgico delle Chiese in Italia dopo il Vaticano II Linee guida, realizzazioni e progetti. Peschiera Borromeo: Vita e Pensiero.

\section{PROCEDENCIA DE LAS ILUSTRACIONES}

Fig. 01-02, 05-10. Archivo del autor.

Fig. 03-04. Riccardo Rovati.

Fig. 11-12. Della Longa et al. 2007.

Fig. 13-15. Chiara Rovati. 